\title{
Rare Atypical Presentation of a Neuroblastoma of Posterior Mediastinum
}

\author{
Vishal Singh ${ }^{1} \quad$ Lamkordor Tyngkan $^{1} \quad$ Abdul Rashid Bhat ${ }^{1}$ \\ ${ }^{1}$ Department of Neurosurgery, Sher E Kashmir Institute of \\ Address for correspondence Vishal Singh, FNB, Department \\ Medical Sciences, Srinagar, India \\ of Neurosurgery, Sher E Kashmir Institute of Medical Sciences, \\ Room 1312, Soura, Srinagar 190011, Jammu and Kashmir, India \\ (e-mail: Dr.vishalsingh1689@gmail.com).
}

Int J Recent Surg Med Sci 2021;7:94-96.

\begin{abstract}
Introduction Neuroblastoma is the third most common malignancy and one of the most common neurogenic tumors of posterior mediastinum in the pediatric age group. A posterior mediastinal tumor causing spinal cord compression is an important example of an oncologic emergency arising from a neurogenic tumor. We present a rare case of posterior mediastinum neuroblastoma, with exclusive lower limb weakness presenting at an unusually older age.

Case Presentation A 6-year-old girl reported with upper back ache and sudden onset progressive bilateral lower limb weakness, with difficulty in urination for 10 days. The weakness had progressed to paraplegia on the day of presentation. On examination, the child was observed to have loss of tone and power in both lower limbs and bilateral extensor plantar reflex. Chest X-ray showed heterogeneous opacity involving most of the left lung. Contrast-enhanced MRI showed posterior mediastinal tumor, extending into spinal canal. Patient underwent D3 to D6 laminectomy with subtotal tumor excision and spinal decompression. Crush biopsy showed round cell tumor, and final histopathological examination revealed poorly differentiated neuroblastoma, which was strongly positive for neuron-specific enolase on immunohistochemistry. The surgery was followed by chemotherapy, and the patient remained symptom free on 2-year follow-up.

Discussion The presenting symptoms in case of thoracic neuroblastoma may include airway obstruction and chronic cough. Sometimes, it may present with weakness, limping, paralysis, and bladder and bowel disturbances in case of spinal cord involvement. Posterior mediastinal neuroblastoma presenting with paraparesis is uncommon. In our case, the child presented with isolated lower limb flaccidity with no other classical symptoms. To the best of our knowledge and thorough study, only four cases of posterior mediastinum neuroblastoma presenting with lower limb paralysis has been

Keywords

- neuroblastoma

- paraplegia

- atypical presentation

- rare

published in the English literature to date.

Conclusion Tumor usually presents with pressure symptoms, caused by the mass in the posterior mediastinum, but it's almost exclusive occurrence in the pediatric population warrants a thorough investigation in patients presenting with not only a symptomatic mass but also exclusive lower limb neurological symptoms.
\end{abstract}

published online

May 12, 2021
DOI https://doi.org/

$10.1055 / \mathrm{s}-0041-1730243$

ISSN 2455-7420
C 2021. Medical and Surgical Update Society.

This is an open access article published by Thieme under the terms of the Creative Commons Attribution-NonDerivative-NonCommercial-License, permitting copying and reproduction so long as the original work is given appropriate credit. Contents may not be used for commercial purposes, or adapted, remixed, transformed or built upon. (https://creativecommons.org/licenses/by-nc-nd/4.0/).

Thieme Medical and Scientific Publishers Pvt. Ltd. A-12, 2nd Floor, Sector 2, Noida-201301 UP, India 


\section{Introduction}

Neuroblastoma is the third most common malignancy in childhood and one of the most common neurogenic tumors of posterior mediastinum in the pediatric age group. ${ }^{1}$ Children commonly present at the age of 2 years, with respiratory symptoms being the usual presentation. ${ }^{2} \mathrm{~A}$ posterior mediastinal tumor causing spinal cord compression is an important example of an oncologic emergency arising from a neurogenic tumor. ${ }^{3}$ We present a rare case of posterior mediastinum neuroblastoma, with exclusive lower limb weakness presenting at an unusually older age.

\section{Case Presentation}

A 6-year-old girl child with no previous significant medical history reported to our OPD with upper back ache and sudden onset progressive bilateral lower limb weakness, with difficulty in urination for 10 days. The weakness had progressed to paraplegia on the day of presentation. She gave a history of fall from height a month back, following which she was asymptomatic for 20 days.

On physical examination, the child was observed to have loss of tone and power in both lower limbs and bilateral extensor plantar reflex. Chest X-ray showed heterogeneous opacity involving most of the left lung (-Fig. 1). Contrast-enhanced MRI showed posterior mediastinal tumor extending into spinal canal (-Figs. 2 and 3). The blood investigations were normal.

Patient underwent D3 to D6 laminectomy with subtotal tumor excision and spinal decompression. The crush biopsy showed round cell tumor, and final histopathological examination revealed poorly differentiated neuroblastoma, which was strongly positive for neuron-specific enolase on immunohistochemistry. The surgery was followed by chemotherapy, and the patient remained symptom free on 2-year follow-up.

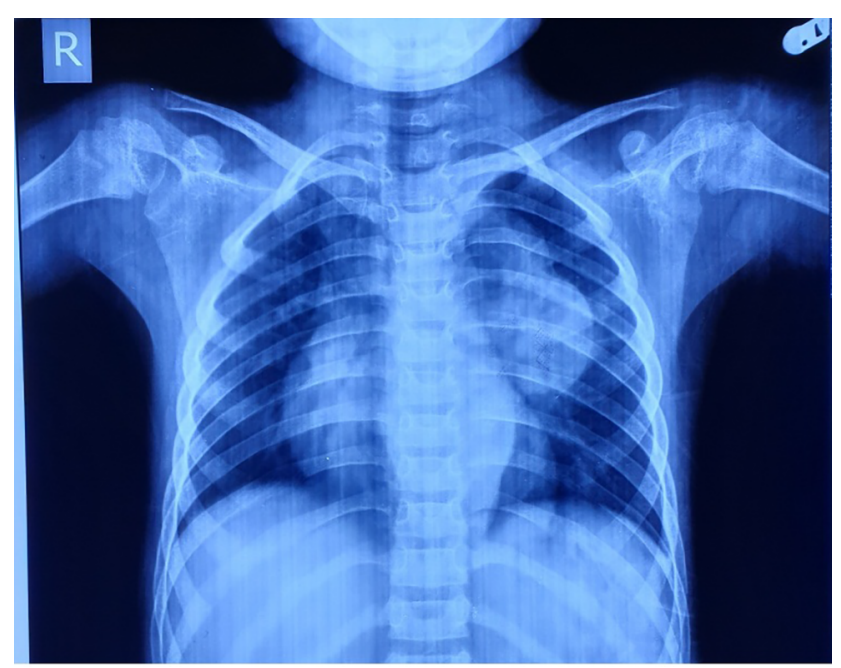

Fig. 1 Chest X-ray.

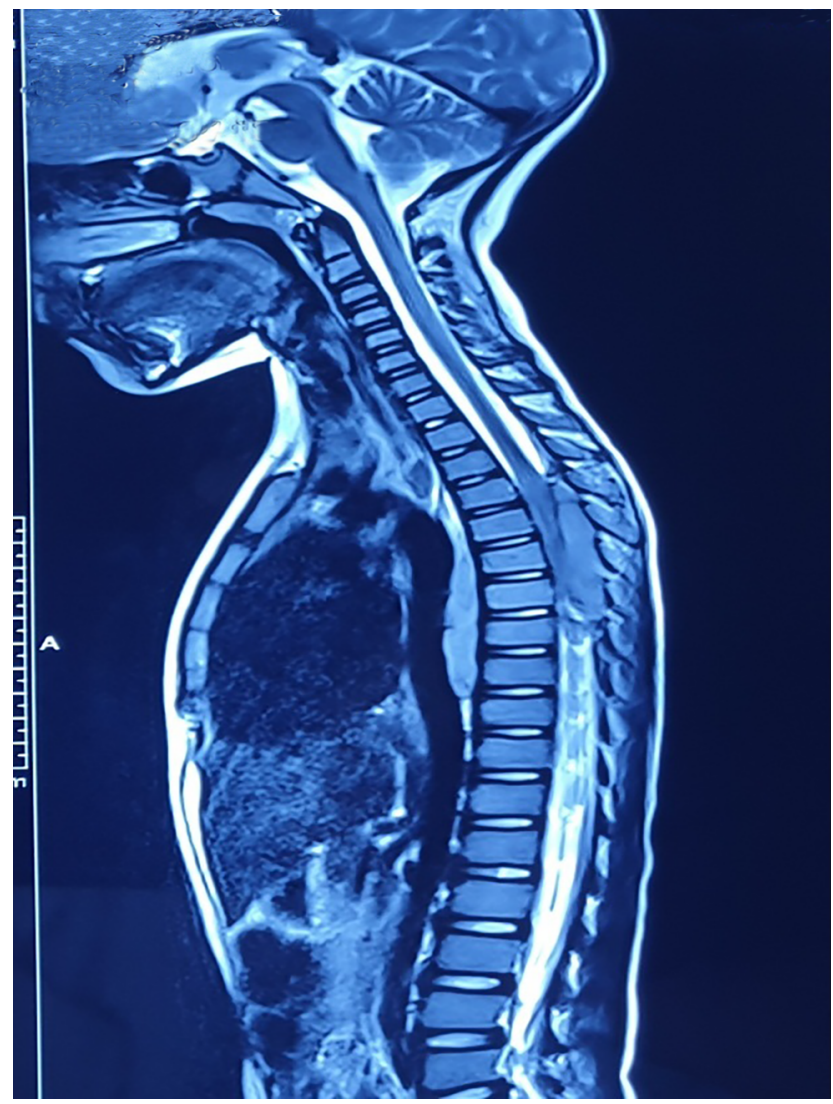

Fig. 2 MRI dorsal spine T2-weighted sagittal image.

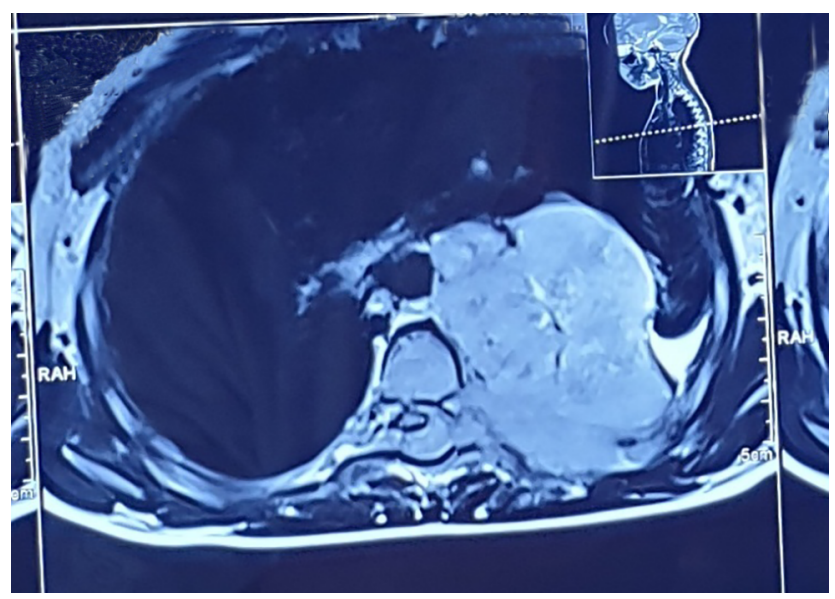

Fig. 3 MRI D6 vertebra T2-weighted axial image.

\section{Discussion}

Neurogenic tumor is one of the most common causes of a posterior mediastinal mass, accounting for almost 90 percent of cases. It is an embryonal tumor of the sympathetic nervous system. ${ }^{4}$ Between 7 and $15 \%$ of children with neuroblastoma present with spinal cord involvement. ${ }^{5}$

It is difficult to detect neuroblastoma compressing the spinal cord in young children due to apparently slow onset, and progress of paralysis delaying the diagnosis and treatment in 
Table 1 List of published cases of neuroblastoma with lower limb paralysis

\begin{tabular}{|l|l|l|l|l|l|l|}
\hline S. no. & Author & year & Age/sex & Presenting complaints & Treatment & Outcome \\
\hline 1 & Mclatchie et al & 1980 & 16 months/M & Progressive paraplegia & $\begin{array}{l}\text { Thoracotomy and } \\
\text { tumor excision }\end{array}$ & $\begin{array}{l}\text { Died at } 27 \text { years } \\
\text { of age }\end{array}$ \\
\hline 2 & Latchaw et al ${ }^{11}$ & 1981 & $\begin{array}{l}\text { a) } 18 \text { months/M } \\
\text { b) } 11 \text { years/M }\end{array}$ & $\begin{array}{l}\text { a) Progressive paraplegia } \\
\text { b) Weakness of lower limbs } \\
\text { with incontinence }\end{array}$ & $\begin{array}{l}\text { a) Decompression } \\
\text { b) Decompressive } \\
\text { laminectomy }\end{array}$ & $\begin{array}{l}\text { a) Not mentioned } \\
\text { b) Not mentioned }\end{array}$ \\
\hline 3 & Rajparath et al ${ }^{9}$ & 2016 & 11 months/M & $\begin{array}{l}\text { Irritability and difficulty in } \\
\text { standing }\end{array}$ & Chemotherapy only & Good \\
\hline 4 & Present case & 2021 & 6 years/F & $\begin{array}{l}\text { Upper back ache and sud- } \\
\text { den onset progressive bilat- } \\
\text { eral lower limb weakness }\end{array}$ & $\begin{array}{l}\text { Subtotal tumor exci- } \\
\text { sion with decompres- } \\
\text { sion for the benefit of } \\
\text { chemotherapy }\end{array}$ & \begin{tabular}{l} 
Good \\
\hline
\end{tabular} \\
\hline
\end{tabular}

previous cases published. ${ }^{6,7}$ In our case, since the age at presentation was atypically a bit higher, we could diagnose the spinal compression early with early intervention.

The presenting symptoms in case of thoracic neuroblastoma may include airway obstruction and chronic cough. Sometimes, it may present with weakness, limping, paralysis, and bladder and bowel disturbances in case of spinal cord involvement. ${ }^{8}$ Posterior mediastinal neuroblastoma presenting with paraparesis is uncommon. ${ }^{9}$ In our case, the child presented with isolated lower limb flaccidity with no other classical symptoms.

Emergency MRI is the imaging of choice. Chemotherapy and laminectomy is the modality of treatment for neuroblastoma causing spinal cord compression. ${ }^{7}$ In our case, we got the MRI as soon as the child presented to us in the OPD, which helped in early laminectomy and tumor excision followed by chemotherapy.

Usually, most recurrences are seen within 2 years of treatment, and if there is no recurrence detected in 5 years after treatment, the disease is said to be cured. ${ }^{10}$ We have not found any recurrence on radiological surveillance till 2 years posttreatment and the child is on follow-up to date.

To the best of our knowledge and thorough study, following are the cases of posterior mediastinum neuroblastoma presenting with lower limb paralysis in the English literature to date ( $\mathbf{- T a b l e ~} \mathbf{1}$ ).

\section{Conclusion}

Although this tumor usually presents with pressure symptoms caused by the mass in the posterior mediastinum, the fact is that, although this tumor is a common cause of posterior mediastinal mass, the tumor itself in the general population is rare. However, it's almost exclusive occurrence in the pediatric population warrants a thorough investigation in patients presenting with not only a symptomatic mass but also exclusive lower limb neurological symptoms.

\section{Conflict of Interest}

None declared.

\section{References}

1 Robert MK, Nelson Textbook of Pediatrics. 20th ed Elsevier; 2015:2461

2 McLatchie GR, Young DG. Presenting features of thoracic neuroblastoma. Arch Dis Child 1980;55(12):958-962

3 Yon DK, Ahn TK, Shin DE, Kim GI, Kim MK. Extragonadal germ cell tumor of the posterior mediastinum in a child complicated with spinal cord compression: a case report. BMC Pediatr 2018;18(1):97

4 Lacayo NJ, Davis KL. Pediatric neuroblastoma. Medscape. 2015 Accessed July 9, 2015 at http://emedicine.medscape.com/ article/988284

5 Shohet JM, Nuchtern JG. In: Post TW, ed. UpToDate. Waltham, MA: UpToDate. Accessed March 9, 2017 at: http://www.uptodate.com/contents/epidemiology-pathogenesis-and-pathology-of-neuroblastoma. Last updated: August 19, 2016

6 Chauhan G, Bhatia P, Bhardwaj AK, Mittal S, Sharma PD. Widely disseminated neuroblastoma presenting as acute flaccid paralysis in a two year old child: a clinical dilemma. Int J Contemporary Med 2014;2:161-163

7 Yahya FS, Al-Shami HA. Posterior mediastinal neuroblastoma masked as flaccid paraparesis in a 3 year child. Neurosciences (Riyadh) 2019;24(4):320-323

8 Castleberry RP. Neuroblastoma. Eur J Cancer 1997;33(9): 1430-1437

9 Rajparath R, Rangesh S, Senthamarai MV. Posterior mediastinal neuroblastoma in an infant presenting with paraparesis: a case report. Pediatric Review: Int J Pediatr Res 2016;9:715-717

10 Brodeur GM, Pritchard J, Berthold F, et al. Revisions of the international criteria for neuroblastoma diagnosis, staging, and response to treatment. J Clin Oncol 1993;11(8):1466-1477

11 Latchaw RE, L'Heureux PR, Young G, Priest JR. Neuroblastoma presenting as central nervous system disease. Am J Neuroradiol 1982;3(6):623-630 